Ambiente \& Água - An Interdisciplinary Journal of Applied Science
ISSN 1980-993X - doi:10.4136/1980-993X
www.ambi-agua.net
E-mail: ambi-agua@agro.unitau.br

\title{
Acúmulo de nutrientes por forrageiras cultivadas em sistema de escoamento superficial para tratamento de esgoto doméstico
}

\author{
doi: 10.4136/ambi-agua.1210 \\ Received: 06 Oct 2013; Accepted: 23 Dec. 2013
}

\begin{abstract}
Aline Azevedo Nazário ${ }^{1 *}$; Giovanni de Oliveira Garcia $^{2}$; Edvaldo Fialho dos Reis $^{2}$; Eduardo de Sá Mendonça ${ }^{3}$; José Guilherme Bergamim Melline ${ }^{3}$

${ }^{1}$ Universidade de Campinas (UNICAMP) - Faculdade de Engenharia Agrícola - Campinas, SP, Brasil Departamento de Água e Solo - Programa de Pós-graduação em Produção Vegetal (CCA-UFES)

${ }^{2,3}$ Universidade Federal do Espírito Santo (UFES) - Centro de Ciências Agrárias - Alegre, ES, Brasil

${ }^{2}$ Departamento de Engenharia Rural

${ }^{3}$ Departamento de Produção Vegetal

*Autor correspondente: e-mail: aline.a.n@ hotmail.com, giovanni.garcia@ufes.br, edreis@cca.ufes.br, eduardo.mendonca@ufes.br,jgmellere@hotmail.com
\end{abstract}

\section{RESUMO}

Atualmente, observa-se deterioração da qualidade das águas, a qual está vinculada ao crescimento populacional e as diversas atividades de produção agroindustriais, neste contexto o trabalho teve como objetivo avaliar o desempenho de três espécies forrageiras utilizadas no tratamento de esgoto doméstico (ED) por meio da disposição no solo aplicando a técnica do escoamento superficial. O experimento foi conduzido no Centro de Ciências Agrárias da Universidade Federal do Espírito Santo usando delineamento experimental inteiramente casualizado com três repetições no esquema de parcela sub-subdividida $3 \times 5 \times 2$. As parcelas, em três níveis, foram compostas pelas espécies Brachiaria brizantha cv. Marandu, Cynodon sp. cv Tifton 85 e Paspalum atratum cv. Pojuca, nas subparcelas, em 5 níveis as taxas de aplicação de efluentes com 7,91; 15,81;23,72; 31,63 e 39,54 $\mathrm{kg} \mathrm{ha}^{-1} \mathrm{dia}^{1}$ de DBO e foram realizados dois cortes no material vegetal em ciclos de 28 dias após o início da aplicação dos tratamentos. Os resultados mostraram que o acúmulo de nutrientes pelas forrageiras foi superior aos relatados em literatura para o capim Marandu, Tifton 85 e Pojuca. Esses resultados reforçam o potencial desses capins para o tratamento de águas residuárias, especialmente efluente de ED.

Palavras-chave: efluentes, disposição no solo, macronutrientes.

\section{Accumulation of nutrients by forage grown in domestic sewage treatment runoff system}

\begin{abstract}
It is evident today that water quality is declining. This deterioration is mainly due to population growth and several aspects of agro-industrial production. This work therefore aimed to evaluate the performance of three forage species which are used for the treatment of domestic sewage (DS) applied to the soil via the superficial runoff technique. This experiment
\end{abstract}


was conducted at the Agrarian Sciences Center of the Federal University of Espírito Santo, Brazil using a completely randomized design experimental delineation, with three replications in a split plot technique $3 \times 5 \times 2$. The plots were composed of Brachiaria brizantha cv. Marandu, Cynodon sp. cv Tifton 85 and Paspalum atratum cv. Pojuca, with five levels of effluent application rates in the subplots: 7.91, 15.81, 23.72, 31.63 and $39.54 \mathrm{~kg} \mathrm{ha}^{-1}$ day $^{1}$ BOD. Two cuts of the plant material were done at 28-day intervals after the treatment application. The results showed that nutrient accumulation by the forage was higher than that reported in literature for Marandu grass, Tifton 85 and Pojuca. These results highlight the potential of these grasses on wastewater treatment, especially DS effluent.

Keywords: effluents, disposal in soil, macronutrients.

\section{INTRODUÇÃO}

A deterioração da qualidade das águas está vinculada ao crescimento populacional das últimas décadas, notadamente nos meios urbanos, juntamente com o incremento de produção nas mais diversas atividades agroindustriais, consequentemente, houve o incremento na geração de grande quantidade de resíduos sólidos, líquidos e gasosos.

Como reflexo do crescimento populacional e da produção de bens de consumo a geração de grande quantidade de resíduos sólidos, líquidos e gasosos toma proporções alarmantes. Em particular, o lançamento de resíduos líquidos, também chamados de água residuária, nos corpos d'água naturais conduz ao estabelecimento de processos poluidores prejudiciais aos sistemas aquáticos que comprometem os usos ao qual aquele manancial estava destinado (Melo e Marques, 2000).

Estudos recentes indicam que a disposição de águas residuárias no solo pode aumentar a produtividade das culturas, melhorar a qualidade dos produtos colhidos, promover melhorias em algumas propriedades físicas do solo, além de possibilitar redução na poluição ambiental (Ribeiro et al., 2009).

O solo e plantas atuam como "filtro vivo" absorvendo e retendo poluentes e organismos patogênicos presentes em resíduos e águas residuárias. Esta disposição completa a sequência de tratamentos de águas residuárias para a redução dos níveis de microrganismos e de vários componentes orgânicos e inorgânicos para níveis aceitáveis (Feigin et al., 1991).

A irrigação e a fertirrigação em pastagem são técnicas cujas aplicações vêm crescendo no Brasil, possibilitando obter forrageiras de melhor valor nutricional, além de favorecer o manejo racional do sistema de produção animal (Drumond et al., 2006).

Os esgotos aplicados no solo conduzem à recarga do lençol subterrâneo e, ou, à evapotranspiração, além de suprirem as necessidades das plantas, tanto em nutrientes, quanto na demanda hídrica, sendo esta dependente da quantidade nutriente para determinação da lâmina aplicada. A capacidade do solo em conduzir à assimilação de compostos orgânicos complexos depende de suas propriedades e condições climáticas. Taxa de infiltração e tipos de cobertura vegetal são fatores importantes no uso do solo como meio de degradação de resíduos orgânicos. Tal degradação requer boa aeração do solo a qual, por sua vez, é inversamente relacionada à umidade do solo. Condições de insuficiente aeração vão conduzir a uma menor capacidade de assimilação do resíduo orgânico pelo solo (Von Sperling, 1996).

Um dos métodos utilizados para disposição de efluentes no solo é o escoamento superficial que consiste na aplicação, controlada, da descarga de águas residuárias, fazendo-as escoarem, no solo, por uma rampa plantada e inclinada, até alcançar canais de coleta. À medida que o efluente percorre o terreno, grande parte evapora, uma menor parte infiltra no solo e o restante é coletado em canais, posicionados na parte inferior da rampa de tratamento (Paganini, 1997). De acordo com Bertoncini (2008), ao utilizar-se do método de escoamento superficial, a rampa deve ser cultivada com capins como a Brachiaria humidicola, Brachiaria 
arrecta, Typha latifolio e Cynodon dactylon (Tifton 85), dentre outros, pois permitem o desenvolvimento dos microrganismos decompositores da matéria orgânica em seu sistema radicular abundante, são bons controladores de erosão e produzem elevada massa verde, absorvendo grandes quantidades de nutrientes do solo.

Dessa forma, há necessidade de informações que visem adequar sistemas de tratamento de efluentes e esclarecer dúvidas que existem frequentemente, como a resposta deste método de tratamento em regiões tropicais. Neste sentido, o trabalho teve como objetivo avaliar a extração de nutrientes de diferentes forrageiras submetidas à irrigação com efluente de esgoto doméstico sobre escoamento superficial.

\section{MATERIAL E MÉTODOS}

O experimento foi realizado na área experimental do Centro de Ciências Agrárias da Universidade Federal do Espírito Santo, no município de Alegre - ES, tendo como coordenadas: latitude $20^{\circ} 45^{\prime} 2,3^{\prime \prime}$ Sul, longitude $41^{\circ} 29^{\prime} 17,7^{\prime \prime}$ Oeste e altitude de 119 metros. O clima da região típico é quente e úmido no verão e seco no inverno, com temperatura anual média é de $23,1^{\circ} \mathrm{C}$ e precipitação média anual de $1.349 \mathrm{~mm}$.

Para montagem do experimento foi construída uma estrutura de alvenaria, contendo 45 unidades experimentais de $1,0 \times 0,2 \times 0,3 \mathrm{~m}$, impermeabilizadas com manta asfáltica e $8 \%$ de declividade. Foram utilizados dois reservatórios de 5.000 litros abastecidos com esgoto doméstico (ED) proveniente de fossas sépticas.

A caracterização química do esgoto doméstico utilizado durante o período experimental está apresentada na Tabela 1 (APHA et al., 1999). O solo de textura média (Franco Arenoso) utilizado no experimento foi coletado no perfil natural de um Latossolo Vermelho-Amarelo na área experimental do Centro de Ciências Agrárias (CCA-UFES), no qual foi seco ao ar, peneirado em malha de $4 \mathrm{~mm}$, e deposto em cada unidade experimental. Uma amostra do solo foi encaminhada ao laboratório onde se determinou os atributos químicos (Tabela 1) conforme metodologia proposta pela EMBRAPA (1997).

Tabela 1. Características químicas do esgoto doméstico e atributos químicos do solo utilizado no preenchimento das rampas cultivadas.

\begin{tabular}{|c|c|c|c|c|c|c|c|c|c|c|c|}
\hline \multicolumn{12}{|c|}{ Esgoto doméstico } \\
\hline pH & $\begin{array}{c}\text { C.E } \\
\left(\mathrm{dS} \mathrm{m}^{-1}\right)\end{array}$ & $\mathbf{N}^{*}$ & $\mathbf{P}$ & K & $\mathbf{C a}$ & $\begin{array}{r}\mathbf{M g} \\
\left.n \operatorname{ng~L}^{-1}\right)\end{array}$ & $\mathrm{Na}$ & $\mathbf{F e}$ & B & Mn & $\begin{array}{c}\text { RAS } \\
\left(\mathrm{cmol}_{\mathrm{c}} \mathrm{L}^{-1}\right)\end{array}$ \\
\hline 7,85 & 0,91 & 227,75 & 18,27 & 56,8 & 0,88 & 0,43 & 3,83 & 0,81 & 0,55 & 0,17 & 4,72 \\
\hline \multicolumn{12}{|c|}{ Solo } \\
\hline $\mathbf{P}$ & $\mathbf{K}$ & $\mathbf{N a}$ & $\mathbf{S}$ & $\mathrm{Fe}$ & $\mathbf{C u}$ & Mn & ISNa & SB & & $\mathbf{V}$ & $\mathbf{m}$ \\
\hline \multirow[t]{4}{*}{2,0} & 97 & 3,0 & 16,0 & 48,0 & 1,2 & 43,0 & 0,47 & 2,75 & & 55,9 & 0,0 \\
\hline & $\mathbf{C a}$ & Mg $\quad H$ & $\mathbf{H}+\mathbf{A l}$ & Al & $\mathbf{T}$ & $\mathbf{t}$ & & $\mathbf{C}$ & & M. O. & pH \\
\hline & & & $-\left(\mathrm{cmol}_{\mathrm{c}} \mathrm{dm}\right.$ & $\left.m^{-3}\right)$ & ------ & ------ & & ------- & dag dm & -3)------- & \\
\hline & 1,7 & 0,8 & 2,2 & 0,0 & 4,91 & 2,75 & & 6,6 & & 11,5 & 5,4 \\
\hline
\end{tabular}

*Semimicro kjeldahl; $\mathrm{CE}=$ condutividade elétrica; $\mathrm{N}=$ nitrogênio; $\mathrm{P}=$ fósforo; $\mathrm{K}=$ potássio; $\mathrm{Ca}=$ cálcio; $\mathrm{Mg}=$ magnésio; $\mathrm{Na}$ = sódio; $\mathrm{Fe}=$ ferro; $\mathrm{B}=$ boro; $\mathrm{Mn}=$ manganês; RAS = razão adsorção de sódio; $\mathrm{S}=$ enxofre; $\mathrm{Cu}=\mathrm{cobre}$; ISNa = índice de saturação de sódio; $\mathrm{SB}=$ soma de bases; $\mathrm{V}=$ saturação de bases; $\mathrm{H}+\mathrm{Al}$ = hidrogênio + alumínio; $\mathrm{Al}=$ alumínio; T = CTC total; $\mathrm{t}=\mathrm{CTC}$ efetiva; $\mathrm{C}=$ carbono; $\mathrm{M}$. O. = matéria orgânica. 
O experimento foi montado no esquema de parcela sub-subdividida $3 \times 5 \times 2$, sendo nas parcelas espécies de forrageiras em três níveis, nas subparcelas taxa de aplicação do esgoto doméstico em cinco níveis e nas sub-subparcelas cortes do material vegetal em dois níveis, num delineamento inteiramente casualizado com três repetições. Os três níveis das espécies de forrageiras foram: Capim Marandu (Brachiaria brizantha cv. Marandu), Tifton 85 (Cynodon sp. cv Tifton 85) e Capim Pojuca (Paspalum atratum cv. Pojuca). Os cinco níveis das taxas de aplicação de esgoto doméstico bruto foram: 7,91; 15,82; 23,73; 31,64 e 39,55 $\mathrm{kg} \mathrm{ha}^{-1} \mathrm{dia}^{1}$ de DBO do ED. Os dois cortes no material vegetal foram em dois ciclos de 28 dias após o início da aplicação do esgoto doméstico bruto.

O plantio das mudas foi feito manualmente. Após o plantio, as mudas foram irrigadas com água provenientes da rede de abastecimento urbana por 28 dias. Transcorridos esse período foi realizado um corte de uniformidade das plantas, para iniciar os tratamentos. Depois de iniciado a aplicação com ED, esta foi à única fonte de água para as plantas, onde uma cobertura com plástico tipo polietileno foi feita para evitar contato com água da chuva, sendo cultivadas no período de verão de dezembro a março.

Os cortes foram realizados a cada 28 dias, perfazendo 2 ciclos de corte. O material vegetal foi cortado manualmente com auxílio de tesoura em todas as unidades experimentais, e acondicionado em sacos de papel e levados para estufa de circulação forçada de ar à temperatura de $55 \pm 2{ }^{\circ} \mathrm{C}$ durante $72 \mathrm{~h}$, para determinação da massa seca (Silva e Queiroz, 2002). O material seco foi triturado em moinho tipo Wiley com peneira de 30 mesh de malha, acondicionado em saco de papel, e levado ao laboratório para determinação dos teores totais de nitrogênio, fósforo, potássio, cálcio, magnésio, enxofre (EMBRAPA, 1999). O acúmulo de nutrientes foi obtido pelo produto dos teores de cada elemento pela produção total de matéria seca por hectare.

Os dados de acúmulo de nutrientes de cada espécie de gramínea, nos cortes efetuados foram analisados pelo teste $\mathrm{F}$ da análise de variância, ao nível de significância de $5 \%$, sendo os valores significativos de caráter quantitativo submetidos à análise de regressão, para determinação do desempenho das forrageiras, decorrente das taxas de aplicação do esgoto doméstico, e os valores de caráter qualitativos submetidos a um teste de média (Tukey) para determinar a diferença entre os tratamentos aplicados.

\section{RESULTADOS E DISCUSSÃO}

Na Figura 1A, nota-se o efeito linear da extração de nitrogênio com o aumento das taxas de aplicação de ED, para ambos os cortes. Para o fator corte em cada nível da taxa de aplicação, verifica-se que o primeiro corte diferiu do segundo corte em todas as taxas de aplicação de ED (Tabela 2).

No estudo do fator corte para cada nível de forrageira, o capim Tifton 85 apresentou maior acúmulo de nitrogênio no primeiro corte seguido de capim Marandu e Pojuca (Tabela 3). No segundo corte o capim Marandu não diferiu do Tifton 85 que superaram o capim Pojuca no acúmulo de nitrogênio. Por sua vez, entre os cortes, o acúmulo de nitrogênio não apresentou diferença para o capim Marandu. No entanto, o Tifton 85 e o capim Pojuca apresentaram superioridade no primeiro corte. Estes resultados se devem as características agronômicas de cada cultivar, o que explica o maior acúmulo pelo capim Tifton, que é um cultivar de elevada exigência nutricional, consequentemente de alto valor nutritivo e grande capacidade de absorver nutrientes. 

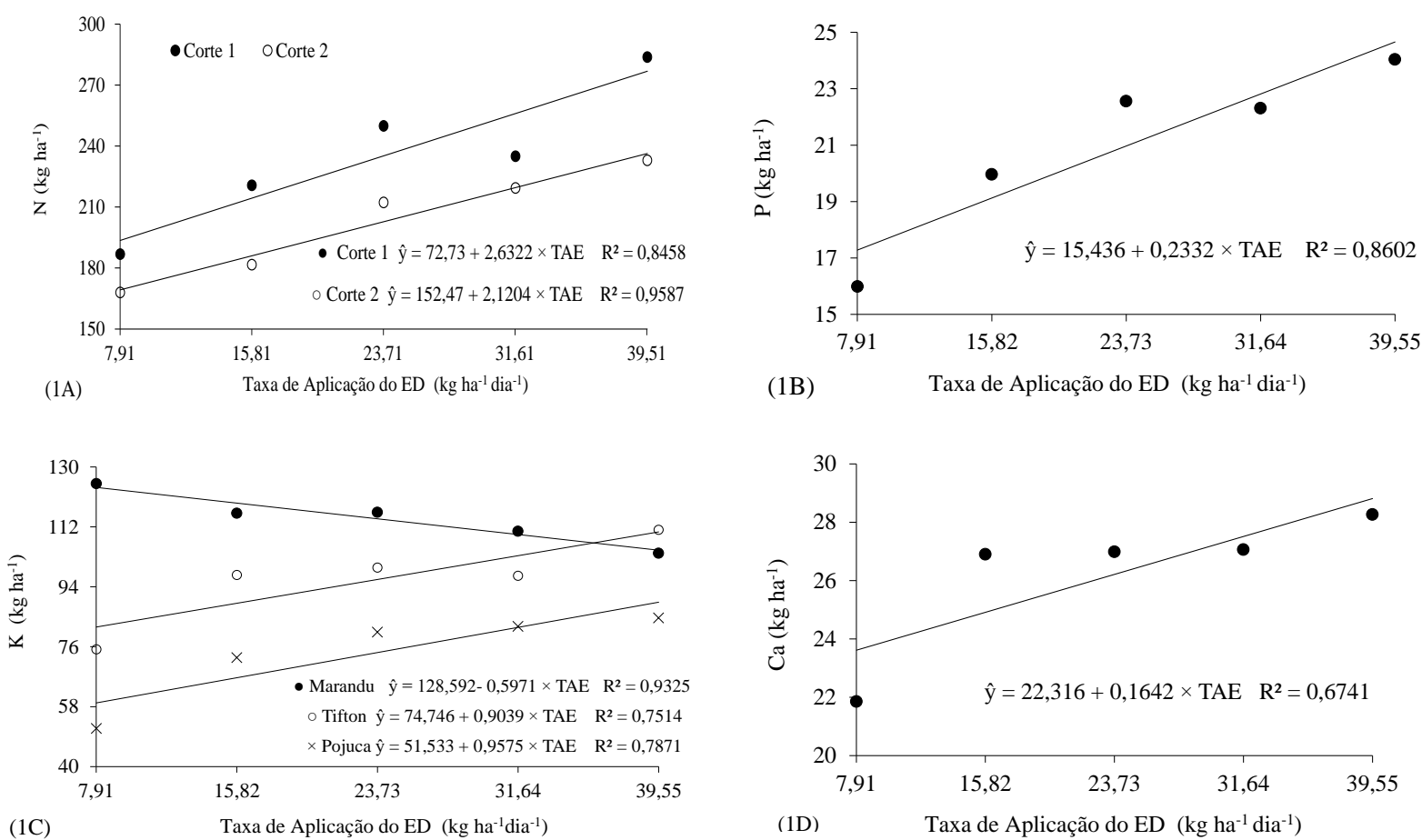

Figura 1. A) Acúmulo de Nitrogênio, B) Fosforo, C) Potássio e D) Cálcio em função da taxa de aplicação de ED para cada corte.

Tabela 2. Valores de acúmulo de nitrogênio $\left(\mathrm{kg} \mathrm{ha}^{-1}\right)$ em função das taxas de aplicação do ED e dos cortes.

\begin{tabular}{c|ccccc}
\hline \multirow{2}{*}{ Cortes } & \multicolumn{5}{|c}{ Taxa de aplicação de ED $\left(\mathbf{k g ~ h a}^{\mathbf{- 1}} \mathbf{d i a}^{\mathbf{- 1}}\right)$} \\
\cline { 2 - 6 } & 7,91 & 15,82 & 23,73 & 31,64 & 39,54 \\
\hline 1 & $186,8 \mathrm{a}$ & $220,6 \mathrm{a}$ & $249,8 \mathrm{a}$ & $234,9 \mathrm{a}$ & $283,7 \mathrm{a}$ \\
2 & $167,9 \mathrm{~b}$ & $181,6 \mathrm{~b}$ & $212,2 \mathrm{~b}$ & $179,3 \mathrm{~b}$ & $202,9 \mathrm{~b}$ \\
\hline
\end{tabular}

*Médias seguidas pela mesma letra minúscula em coluna não diferem entre si, ao nível de 5\% de probabilidade pelo teste de Tukey.

Tabela 3. Valores de acúmulo de nitrogênio $(\mathrm{N})$, fósforo $(\mathrm{P})$, cálcio $(\mathrm{Ca})$, Magnésio $(\mathrm{Mg})$ e enxofre $(\mathrm{S})$ $\left(\mathrm{kg} \mathrm{ha}^{-1}\right)$ em função das forrageiras e dos cortes.

\begin{tabular}{|c|c|c|c|c|c|c|}
\hline \multirow{3}{*}{ Forrageira } & \multicolumn{2}{|c|}{$\mathbf{N}$} & \multicolumn{2}{|c|}{$\mathbf{P}$} & \multicolumn{2}{|c|}{$\mathbf{C a}$} \\
\hline & \multicolumn{6}{|c|}{ Cortes } \\
\hline & $1^{\circ}$ & $2^{\circ}$ & $1^{\circ}$ & $2^{\circ}$ & $1^{\circ}$ & $2^{\circ}$ \\
\hline B. brizantha $\mathrm{cv}$. Marandu & $228,5 \mathrm{Ab}$ & $227,6 \mathrm{Aa}$ & $24,1 \mathrm{Ba}$ & $29,9 \mathrm{Aa}$ & $24,6 \mathrm{Ab}$ & $23,4 \mathrm{Aa}$ \\
\hline Cynodon sp. cv. Tifton 85 & $282,3 \mathrm{Aa}$ & $221,8 \mathrm{Ba}$ & $19,9 \mathrm{Bb}$ & $23,5 \mathrm{Ab}$ & $25,9 \mathrm{Ab}$ & $21,6 \mathrm{Ba}$ \\
\hline P. atratum cv. Pojuca & $194,8 \mathrm{Ac}$ & $116,8 \mathrm{Bb}$ & $12,1 \mathrm{Bc}$ & $16,3 \mathrm{Ac}$ & $40,1 \mathrm{Aa}$ & $21,6 \mathrm{Ba}$ \\
\hline \multirow{3}{*}{ Forrageira } & & \multicolumn{2}{|c|}{$\mathrm{Mg}$} & \multicolumn{2}{|c|}{$\mathrm{S}$} & \\
\hline & & \multicolumn{4}{|c|}{ Cortes } & \\
\hline & & $1^{\circ}$ & $2^{\circ}$ & $1^{\circ}$ & $2^{\circ}$ & \\
\hline B. brizantha $\mathrm{cv}$. Marandu & & $29,7 \mathrm{Ab}$ & $23,8 \mathrm{Ba}$ & $19,1 \mathrm{Aa}$ & $11,2 \mathrm{Bb}$ & \\
\hline Cynodon sp. cv. Tifton 85 & & $19,3 \mathrm{Ac}$ & $14,0 \mathrm{Bb}$ & $15,4 \mathrm{Aa}$ & $18,2 \mathrm{Aa}$ & \\
\hline P. atratum cv. Pojuca & & $33,4 \mathrm{Aa}$ & $17,1 \mathrm{Bb}$ & $13,3 \mathrm{Aa}$ & $8,3 \mathrm{Ab}$ & \\
\hline
\end{tabular}

*Médias seguidas pela mesma letra minúscula em coluna, maiúscula em linha não diferem entre si, ao nível de 5\% de probabilidade pelo teste de Tukey. 
Galzerano e Morgado (2007) relataram em suas considerações finais que para o capim Tifton 85 a produção e qualidade deste aumentam à medida que se eleva a quantidade de nitrogênio aplicada, indicando que para obtenção de bons índices de produção, a adubação nitrogenada torna-se prática indispensável.

Os resultados de acúmulo de nitrogênio para o capim Marandu, média de 3,26 dag kg ${ }^{-1}$ $\left(228,08 \mathrm{~kg} \mathrm{ha}^{-1}\right)$, capim Tifton média de 3,54 dag kg-1 $\left(252,06 \mathrm{~kg} \mathrm{ha}^{-1}\right)$ estão acima do considerado adequado para Brachiaria brizantha $\left(1,3-2,0\right.$ dag $\left.\mathrm{kg}^{-1}\right)$ e para Tifton $85(2,0-2,6$ dag $\mathrm{kg}^{-1}$ ), segundo Werner et al. (1996).

Os dados apresentados neste trabalho corroboram com os obtidos por Silva Neto et al. (2010) que verificaram, com o uso de esgoto de lavagem de frigorífico em área com capim Brachiaria, aumento nos teores de nitrogênio foliar com as maiores doses de efluente aplicado, nos dois cortes realizados durante o trabalho. Tais autores atribuíram esse resultado à disponibilização do nitrogênio pelo esgoto de frigorífico, na forma mineral assimilada pela planta.

De acordo com trabalho de Primavesi et al. (2004), os valores de extração de nitrogênio para o capim Coastcross variou de 69 a $475 \mathrm{~kg} \mathrm{ha}^{-1}$ quando se usou uréia no solo, onde os autores justificam esta variação de acordo com a produção de forragem, onde quanto maior a produção, mais elevada será a remoção de nutrientes pela forrageira. Os resultados destes autores se assemelham com os do presente trabalho, onde o maior acúmulo de nitrogênio pelas forrageiras foi exatamente no primeiro ciclo de corte que obteve maior rendimento de matéria seca.

Observa-se na Figura 1B que o aumento das taxas de aplicação de ED proporcionou efeito linear no acúmulo de fósforo atingindo valor máximo quando aplicada a taxa de ED de $37,67 \mathrm{~kg} \mathrm{ha}^{-1} \mathrm{dia}^{-1}$. Estes resultados encontram-se acima do adequado para o estado nutricional das forrageiras em estudo, onde Werner et al. (1996) apresentam faixas que variam de $0,08-0,3$ dag $\mathrm{kg}^{-1}$ dependendo da forrageira avaliada, e os valores do presente trabalho para acúmulo de fósforo nas plantas em estudo com a menor taxa de ED foi maior que $15 \mathrm{~kg}$ $\mathrm{ha}^{-1}\left(0,30 \mathrm{dag}_{\mathrm{kg}}{ }^{-1}\right)$, ou seja, a menor taxa de aplicação de ED já atenderia a demanda de fósforo das forrageiras. Porém, sintomas de toxidez não foram observados, fato que pode ser justificado pelo $\mathrm{pH}$ do solo, onde a média de $\mathrm{pH}$ 4,82 impediu a disponibilidade em excesso do nutrientes para as plantas em estudo.

Por outro lado, Queiroz et al. (2004) trabalhando com capim Tifton 85 submetido à aplicação de água residuária de suinocultura e água da rede de abastecimento, obteve valores médios de 0,37 e $0,34 \mathrm{dag} \mathrm{kg}^{-1}$, respectivamente, de concentração de fósforo total nas folhas.

Com base nos resultados do estudo do acúmulo de fósforo em função das forrageiras e dos cortes na Tabela 3, observa-se que o capim Marandu apresentou as maiores médias em relação aos capins Tifton seguido do Pojuca dentro de cada corte. Por outro lado, entre os cortes as três forrageiras apresentaram maior extração de fósforo no segundo corte.

A diferença de acúmulo de fósforo pelas forrageiras entre os cortes se justifica pelo efeito concentração do fósforo nas plantas, onde este estava mais facilmente disponível devido a maior presença do elemento no solo, o que ocorreu no final do experimento (Tabela 4).

$\mathrm{Na}$ disposição dos esgotos no solo por escoamento superficial, a remoção do fósforo dá-se: por precipitação química com alumínio e ferro e na forma de fosfato de cálcio, $\mathrm{Ca}_{3}\left(\mathrm{PO}_{4}\right)_{2}$ por adsorção no complexo de troca e na superfície das argilas, e por absorção pela vegetação em crescimento nas rampas de tratamento (Paganini, 1997). Para que este último fator de remoção do fósforo possa ser potencializado, recomenda-se que a frequência de cortes e a retirada da biomassa sejam as mais numerosas possíveis, minimizando sua concentração no solo da área de tratamento e, assim, possibilitando maior sustentabilidade ao sistema (Loures et al., 2006) 
Tabela 4. Atributos químicos do solo antes e após a aplicação das doses de ED para cada forrageira em estudo.

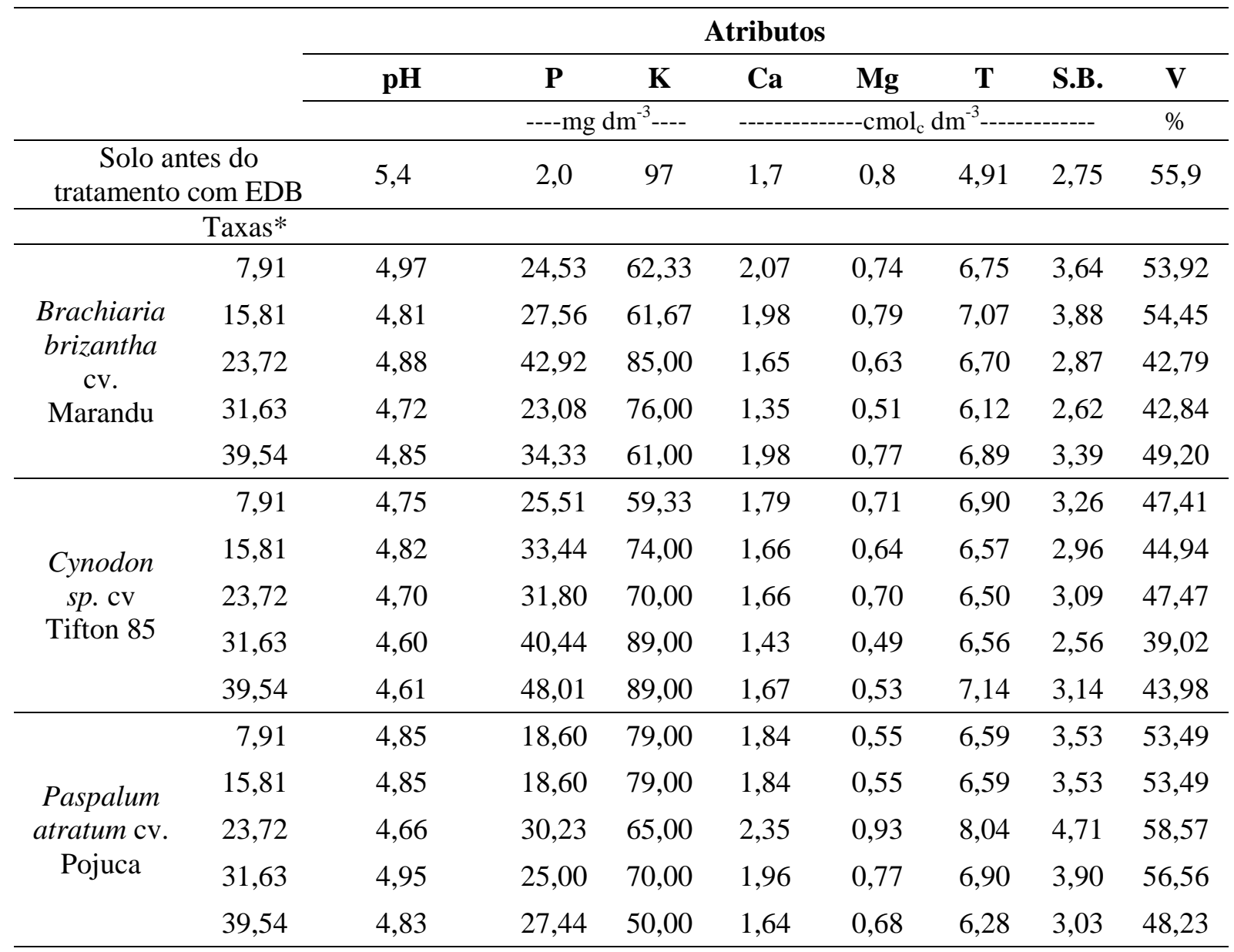

*Taxas $\left(\mathrm{kg} \mathrm{ha}^{-1} \mathrm{dia}^{-1}\right)$; EMBRAPA (1997).

Matos et al. (2010), avaliando o capim Tifton 85, verificaram sua eficiência de adaptação nos sistemas alagados construídos, para o tratamento de águas residuárias de laticínios, justamente porque a forrageira foi capaz de remover grandes quantidades de fósforo. Porém, no presente trabalho observa-se que o capim Marandu obteve um maior acúmulo de fósforo que o capim Tifton 85, o que se explica pela diferença media do $\mathrm{pH}$ para cada uma das forrageiras, mesmo os valores de $\mathrm{pH}$ se apresentando baixo, ao relacionar o $\mathrm{pH}$ do solo do capim Marandu média de 4,85 e do capim Tifton 85 média de 4,65 o valor um pouco mais elevado para capim Marandu pode ter influenciado na disponibilidade de fósforo para as plantas.

Haddad e Castro (1998) apresentaram uma revisão de trabalhos envolvendo espécies de forrageiras passíveis de serem fenadas e suas características nutricionais em função da idade de corte. Para o capim Coastcross, foi encontrado um teor de fósforo de $0,2 \mathrm{dag} \mathrm{kg}^{-1}$, nos cortes efetuados aos 40 e 50 dias de idade; este valor é $32 \%$ inferior à concentração média mais baixa obtida neste trabalho, sob a menor taxa de aplicação 7,91 $\mathrm{kg} \mathrm{ha}^{-1} \mathrm{dia}^{-1}$.

Fonseca et al. (2000), em estudo conduzido com o capim Coastcross e aplicação de esgoto doméstico, verificou concentrações médias de fósforo de $0,37 \mathrm{dag} \mathrm{kg}^{-1}$, sob a taxa de aplicação $0,24 \mathrm{~m}^{3} \mathrm{~h}^{-1} \mathrm{~m}^{-1}$; de $0,38 \mathrm{dag} \mathrm{kg}^{-1}$, sob a taxa $0,36 \mathrm{~m}^{3} \mathrm{~h}^{-1} \mathrm{~m}^{-1}$ e de $0,22 \mathrm{dag} \mathrm{kg}^{-1}$ para a testemunha. Em comparação com este trabalho apenas a testemunha foi $25 \%$ inferior aos valores da menor taxa de aplicação de ED de 7,91 $\mathrm{kg} \mathrm{ha}^{-1}$ dia $^{-1}$, com acúmulo de 15,98 $\mathrm{kg} \mathrm{ha}^{-1}$ $\left(0,29 \mathrm{dag} \mathrm{kg}^{-1}\right)$. 
Na Figura 1C nota-se que o efeito linear para o acúmulo de potássio das taxas de aplicação de ED em cada cultivar estudada, onde o acúmulo de potássio mostrou diferença entre as forrageiras estuda, uma das possíveis explicações é a forma de absorção de cada elemento pelo cultivar. O capim Tifton 85 é reconhecido como um cultivar de elevada exigência nutricional, consequentemente de alto valor nutritivo e grande capacidade de absorção de nutrientes. A Brachiaria sp. é altamente resistente e competidora, podendo se adaptar a adversas condições de nutrientes e o capim Pojuca se adapta em condições de elevado lençol freático, e possivelmente, a grandes taxas de material orgânico como aporte de nutrientes.

Em comparação com estudos realizados por Werner et al. (1996), observa-se que a capacidade de absorção de nutrientes das forrageiras estão adequadas, onde o capim Marandu obteve média de $114,4 \mathrm{~kg} \mathrm{ha}^{-1}\left(1,65 \mathrm{dag} \mathrm{kg}^{-1}\right)$, capim Tifton 85 de $195 \mathrm{~kg} \mathrm{ha}^{-1}\left(1,41 \mathrm{dag} \mathrm{kg}^{-1}\right)$ e capim Pojuca de $73,8 \mathrm{~kg} \mathrm{ha}^{-1}\left(1,39 \mathrm{dag} \mathrm{kg}^{-1}\right)$, sendo os níveis adequados Tifton $85 \mathrm{de}$ 1,3-3,0 dag kg-1 e Brachiaria 1,2-3,0 dag kg-1. Dessa forma, as taxas de aplicação de ED, forneceram quantidades adequadas de potássio passível de ser absorvido pelos cultivares, ou seja, a menor taxa de aplicação forneceu a concentração de potássio para desenvolvimento dos cultivares.

Estes resultados corroboram com trabalho de Erthal et al. (2010), ao avaliar capim Tifton 85 e aveia preta sobre taxas de água residuária de bovinocultura e água (sem adição efluente), onde a concentração de potássio foi semelhante em ambos os trabalhos quando aplicação de efluente. Logo, mostra o elevado aporte de potássio ao uso efluente, seja de origem doméstica ou animal, evidenciando assim uma fonte deste para adubação das forrageiras.

Para a taxa de aplicação do ED (Figura 1D), nota-se a relação linear no acúmulo de cálcio com o aumento das taxas de aplicação de ED. A elevação do acúmulo é em função do decorrente aumento da oferta de cálcio com o incremento das doses de aplicação do ED (Tabela 4). Resultados semelhantes foram descritos por Erthal et al. (2010), para o capim Tifton 85 sob crescentes taxas de efluente de bovinocultura.

O capim Pojuca obteve as maiores médias em relação ao capim Marandu e Tifton no primeiro corte, onde no segundo corte todas as forrageiras não mostraram diferenciação entre médias. Por outro lado o capim Tifton e capim Pojuca apresentaram as maiores médias no primeiro corte que no segundo, já o capim Marandu manteve o padrão de extração de cálcio entre os dois cortes (Tabela 3).

Os resultados deste trabalho estão adequados quanto às exigências nutricionais de todas as forrageiras estudas, segundo Werner et al. (1996). No geral, os valores obtidos para o capim Tifton estão semelhantes aos relatados nos trabalhos de Queiroz et al. (2001); Oliveira et al. (2000) e Ribeiro et al. (2000).

Os valores de acúmulo de magnésio diferiram do primeiro para o segundo corte em todas as forrageiras avaliadas (Tabela 3). Onde no primeiro corte o capim Pojuca diferiu dos demais. Já para o segundo corte apenas o capim Marandu diferiu o acúmulo de magnésio das demais. Estes resultados se explicam possivelmente como para os demais nutrientes descritos pelas características agronômicas de cada cultivar em estudo, como por exemplo, ao processo fotossintético de cada espécie. O magnésio possui importante papel na síntese protéica, atua como ativador enzimático, além de participar da constituição da molécula de clorofila, onde em cada espécie é requerido em proporções diferentes (Malavolta, 1980).

Ressaltando neste trabalho que o capim Tifton 85 , foi o cultivar de menor extração do magnésio no primeiro corte, fato este não observado para os demais elementos já mencionados, uma vez que se espera uma alta extração pelo cultivar, devido a sua elevada exigência nutricional. Porém, em estádios de crescimento mais avançados, o metabolismo das plantas é reduzido, interferindo na absorção de alguns elementos, fato este que pode ter 
ocorrido com o cultivar em estudo. Outro fator a considerar é a competição do magnésio com cálcio, ou seja, maior competição do $\mathrm{H}^{+}$com os cátions.

A redução nos teores de magnésio com a idade pode também estar relacionado provavelmente com o processo natural de diluição do elemento na quantidade de matéria seca produzida. Resultados semelhantes foram encontrados por Oliveira et al. (2000) avaliando o valor nutricional do capim Tifton 85 , onde os autores observaram diminuição dos teores de magnésio após os 14 dias de desenvolvimento da planta.

Queiroz et al. (2004), ao avaliarem o acúmulo de magnésio em rampas de escoamento superficial, observaram também maior acúmulo pelo capim Brachiaria, em ambos os tratamentos com água residuária de suinocultura, em relação ao capim Tifton 85 .

De acordo com os resultados obtidos os valores de acúmulo de magnésio estão dentro da faixa nutricional considerada adequada por Werner et al. (1996) que é de $\left(0,15-0,4 \mathrm{dag} \mathrm{kg}^{-1}\right)$, e os valores médios para as forrageiras estudadas ficaram em torno de $26,78 \mathrm{~kg} \mathrm{ha}^{-1}(0,39 \mathrm{dag}$ $\left.\mathrm{kg}^{-1}\right)$ para o capim Marandu, $16,66 \mathrm{~kg} \mathrm{ha}^{-1}\left(0,24 \mathrm{dag} \mathrm{kg}^{-1}\right)$ para o capim Tifton e 25,28 kg ha $\left(0,38 \mathrm{~kg} \mathrm{ha}^{-1}\right)$ para capim Pojuca. Porém, superiores aos encontrados por Queiroz et al. (2001) para forrageiras sob aplicação de efluente de suinocultura.

Em trabalho desenvolvido por Erthal et al. (2010), ao avaliar capim Tifton 85 e aveia preta sobre taxas de água residuária de bovinocultura e água (sem adição efluente), todos os resultados encontrados pelos autores independente dos tratamentos aplicados e tipo de irrigação, os valores de magnésio ficaram bem abaixo dos relatos neste experimento, onde para o capim Tifton 85 a maior média apresentada foi de $0,19 \mathrm{~kg} \mathrm{ha}^{-1}$ e para aveia-preta de $0,06 \mathrm{~kg} \mathrm{ha}^{-1}$, os menores valores encontrados podem ser em função da quantidade do nutriente presente na água residuária de bovinocultura, assim como a interação desta com o tipo de solo utilizado um Argissolo Vermelho Escuro Eutrófico Tb.

$\mathrm{Na}$ Tabela 3 para o enxofre, observa-se que o capim Marandu diferiu ao logo dos períodos de avaliação, e no segundo corte o capim Tifton 85 diferiu dos demais cultivares avaliados. Essa relevância de acúmulo do Tifton 85 se deve principalmente ao fato deste cultivar ser uma planta com elevada exigência nutricional, fazendo que mecanismos intrínsecos da planta, como por exemplo, sistemas radiculares muito desenvolvidos absorvam enxofre da água utilizada na irrigação ou do solo.

Ferreira et al. (2003) mostra que a utilização do lodo oriundo de estações de tratamento de despejos de curtume, como fonte de matéria orgânica e nutriente no solo, pode ser recomendada pelo valor corretivo e fertilizante que estes apresentam, bem como pela capacidade da macro e microbiota do solo de decompor os materiais orgânicos. Logo, o acúmulo de enxofre pelas forrageiras está associado ao aporte e a disponibilidade deste para as plantas, devido ao processo de mineralização (Souza et al., 2005).

\section{CONCLUSÃO}

Todas as taxas de aplicação de esgoto doméstico forneceram nutrientes necessários aos cultivares estudados, onde o incremento das taxas foi correspondente ao desenvolvimento das forrageiras. Ressalta-se apenas uma exceção ao cultivar Marandu, onde a menor taxa de aplicação de esgoto doméstico bruto foi a que proporcionou o maior acúmulo de potássio pelas plantas.

O acúmulo de nutrientes em função das taxas de aplicação de esgoto doméstico (7,91; 15,$82 ; 23,73 ; 31,64$ e $39,55 \mathrm{~kg} \mathrm{ha}^{-1} \mathrm{dia}^{1}$ de DBO) para os cultivares Marandu, Tifton 85 e Pojuca estão acima dos mencionados em literatura para nitrogênio, fósforo, enxofre, manganês, ferro e cobre. Já para potássio, cálcio e magnésio estão de acordo com os valores médios relatados para as forrageiras. Logo, a utilização do esgoto doméstico nestas gramíneas 
é uma importante alternativa para aproveitamento e destinação deste resíduo, com valores de acúmulo de nutrientes adequados para desenvolvimento dos cultivares.

\section{AGRADECIMENTOS}

Ao Conselho Nacional de Desenvolvimento Científico e Tecnológico (CNPq) e Fundação de Amparo à Pesquisa do Espírito Santo (FAPES) pelo auxílio financeiro no desenvolvimento da pesquisa.

\section{REFERÊNCIAS}

AMERICAN PUBLIC HEALTH ASSOCIATION - APHA; AMERICAN WATER WORKS ASSOCIATION - AWWA; WATER ENVIRONMENT FEDERATON - WEF. Standard methods for the examination of water and wastewater. 14. ed. Washington, DC., 1999.

BERTONCINI, E. I. Tratamento de efluentes e reuso da água no meio agrícola. Revista Tecnologia \& Inovação Agropecuária, São Paulo, v. 1, n . 1, p. 152-169, 2008.

DRUMOND, L. C. D.; ZANINI, J. R.; AGUIAR, A. P. A.; RODRIGUES, G. P.; FERNANDES, A. L. T. Produção de matéria seca em pastagem de tifton 85 irrigada, com diferentes doses de dejeto líquido de suíno. Engenharia Agrícola, Jaboticabal, v. 26, n. 2, p. 426-433, 2006. http://dx.doi.org/10.1590/S0100-69162006000200009

EMPRESA BRASILEIRA DE PESQUISA AGROPECUÁRIA - EMBRAPA. Manual de análises de solo. Rio de Janeiro: EMBRAPA/SNCS, 1997. 212p.

EMPRESA BRASILEIRA DE PESQUISA AGROPECUÁRIA - EMBRAPA. Manual de análises químicas de solo, plantas e fertilizantes. Brasília: Embrapa Comunicação para transferência tecnologia, 1999. 370p.

ERTHAL, V. J. T.; FERREIRA, P. A.; PEREIRA, O. G.; MATOS, A. T. Características fisiológicas, nutricionais e rendimento de forrageiras fertirrigadas com água residuária de bovinocultura. Revista Brasileira de Engenharia Agrícola e Ambiental, Campina Grande, v. 14, n. 5, p. 458-466, 2010. http://dx.doi.org/10.1590/S141543662010000500002

FEIGIN, A.; RAVINA, I.; SHALHEVET, J. Irrigation with treated sewage effluent: management for environmental protection. Berlin: Springer-Verlag, 1991. 224p.

FERREIRA, A. S. et al. Alterações de atributos químicos e biológicos de solo e rendimento de milho e soja pela utilização de resíduos de curtume e carbonífero. Revista Brasileira de Ciências do Solo, Viçosa, v. 27, n. 4, p. 755-763, 2003. http://dx.doi.org/10.1590/S0100-06832003000400020

FONSECA, S. P. P.; SOARES, A. A.; CHERNICHARO, C. L.; VIANNA, M. R.; MATOS, A. T. Comparação de metodologias para dimensionamento do tratamento de esgoto doméstico pelo método de escoamento superficial. In: CONGRESSO INTERAMERICANO DE ENGENHARIA SANITÁRIA E AMBIENTAL, 2000, Porto Alegre. Anais... Porto Alegre: [s.n.], 2000.

GALZERANO, L.; MORGADO, E. Influence of Nitrogen on yield and quality of Tifton 85 (Cynodon spp.) grass. Revista Electrónica de Veterinária, Málaga, v. 8, n. 2, p. 1-8, 2007. 
HADDAD, C. M.; CASTRO, F. G. F. Produção de feno. In: SIMPÓSIO SOBRE MANEJO DA PASTAGEM, 15., 1998, Piracicaba. Anais... Piracicaba: FEALQ, 1998. p. 151.

LOURES, A. P. S.; SOARES. A. A.; MATOS. A. T. de; CECON. P. R.; PEREIRA. O. G. Remoção de fósforo em sistemas de tratamento de esgoto doméstico, por escoamento superficial. Revista Brasileira de Engenharia Agrícola e Ambiental, Campina Grande, v. 10, n. 3, p. 706-714, 2006. http://dx.doi.org/10.1590/S141543662006000300025

MALAVOLTA, E. Elementos de nutrição mineral de plantas. São Paulo: Agronômica Ceres, 1980. 251p.

MATOS, A. T.; ABRAHÃO, S. S.; PAOLA A. V. Lo M.; SARMENTO, A. P.; MATOS, M. P. de. Capacidade extratora de plantas em sistemas alagados utilizados no tratamento de águas residuárias de laticínios. Revista Brasileira de Engenharia Agrícola e Ambiental, Campina Grande, v. 14, n. 12, p. 1311-1317, 2010. http://dx.doi.org/10.1590/S1415-43662010001200009

MELO, W. J.; MARQUES, M. O. Potencial do lodo de esgoto como fontes de nutrientes para as plantas. In: BETTIOL, W.; CAMARGO, O. A. (Org.). Impacto ambiental do uso agrícola do lodo de esgoto. Jaguariúna: EMBRAPA, 2000. Cap. 5. p. 109-141.

OLIVEIRA, M. A.; PEREIRA, O. G.; GARCIA, R.; OBEID, J. A.; CECON, P. R.; MORAES, S. A. et al. Rendimento e valor nutritivo do capim tifton 85 (Cynodon spp.) em diferentes idades de rebrota. Revista Brasileira de Zootecnia, Piracicaba, v. 29, n. 6, p. 1949-1960, 2000.

PAGANINI, W. S. Disposição de esgoto no solo, através de escoamento à superfície, com utilização de gramíneas: avaliação do processo quanto aos aspectos sanitários, operacionais, construtivos e de manutenção. 1997. 197f. Dissertação (Mestrado em Engenharia Civil) - Programa de Pós-graduação em Engenharia Civil, Universidade de São Paulo, 1997.

PRIMAVESI, A. C.; PRIMAVESI, ODO.; CORRÊA, L. de A.; CANTARELLA, H.; SILVA, A. G. da; FREITAS, A. R. de et al. Adubação nitrogenada em Capim-Coastcross: efeitos na extração de nutrientes e recuperação aparente do nitrogênio. Revista Brasileira de Zootecnia, Piracicaba, v. 33, n. 1, p. 68-78, 2004. http://dx.doi.org/10.1590/S1516-35982004000100010

QUEIROZ, F. M.; MATOS, A. T.; PEREIRA, O. G.; OLIVEIRA, R. A. The dry matter yield of forage-grass species in overland flow treatment using swine wastewater. In: SOARES, A. A.; SATURNINO, H. M. (Org.). Enviroment and the water: competitive use and conservation strategies for water and natural resources. Brasília: ABID, 2001. P. 166-172.

QUEIROZ, F. M.; MATOS, A. T.; PEREIRA, O. G.; OLIVEIRA, R. A.; LEMOS, A. F. Características químicas do solo e absorção de nutrientes por gramíneas em rampas de tratamento de águas residuárias da suinocultura. Engenharia na Agricultura, Viçosa, v. 12, n. 2, p. 77-90, 2004.

RIBEIRO, K. G.; PEREIRA, O. G.; GARCIA, R.; VALADARES FILHO, S. C.; CECON, P. R. Composição e extração mineral do capim-tifton 85, em três idades de rebrota, sob cinco doses de nitrogênio. In: REUNIÃO ANUAL DA SOCIEDADE BRASILEIRA DE ZOOTECNIA, 37., 2000, Viçosa. Anais... Viçosa: SBZ, 2000. p. 55. 
RIBEIRO, M. S. et al. Efeitos de águas residuárias de café no crescimento vegetativo de cafeeiros em seu primeiro ano. Engenharia Agrícola, Jaboticabal, v. 29, n. 4, p 569-577, 2009. http://dx.doi.org/10.1590/S0100-69162009000400007

SILVA NETO, S. P.; SILVA, J. E. C.; SANTOS, A. C.; CASTRO, J. G. D.; DIM, V. P.; ARAÚJO, A. dos S. Características agronômicas e nutricionais do capim-Marandu em função da aplicação de resíduo líquido de frigorífico. Acta Scientiarum. Animal Sciences, Maringá, v. 32, n. 1, p. 9-17, 2010.

SILVA, D. J.; QUEIROZ, A. C. Análise de alimentos (métodos químicos e biológicos). 3. ed. Viçosa, MG: UFV, 2002. 235 p.

SOUZA, E. R. B. de; BORGES, J. D.; LEANDRO, W. M.; OLIVEIRA JÚNIOR, J. P. de; OLIVEIRA, I. P. de; XIMENES, P. A. et al. Teores de metais tóxicos nas folhas de plantas de milho fertilizadas com lodo de curtume. Pesquisa Agropecuária Tropical, v. 35, n. 2, p. 117-122, 2005.

VON SPERLING, M. Princípios básicos do tratamento de esgotos. Belo Horizonte: Departamento de Engenharia sanitária e ambiental. Universidade Federal de Minas Gerais, 1996. Vol. 2, 211p.

WERNER, J. C.; PAUlinO, V. T.; CANTARELla, H.; ANDRADE, N. O.; QUAGGIO, J. A. Forrageiras. In: RAIJ, B. Van; CANTARELA, H.; QUAGGIO, J. A.; FURLANI, A. M. C. (Ed.). Recomendações de adubação e calagem para o Estado de São Paulo. 2. ed. Campinas: Fundação IAC, 1996. p. 263-274. (IAC Boletim Técnico, 100). 